\title{
Analysis of Methoxymethylbenzoguanamine Resins Using Matrix-Assisted Laser Desorption/Ionization Time-of-Flight Mass Spectrometry and Electrospray Ionization Mass Spectrometry
}

\author{
Shoji Okuno, ${ }^{\text {a) }}$ Akito Shiokawa, ${ }^{\text {a) Kimiya Ogawa, }}$, Hidenobu Irie, \\ Masayoshi Oнmoto, ${ }^{\text {b) }}$ Hiroki Fujiwara, ${ }^{\text {b) }}$ and Ryuichi Arakawa*b)
}

(Received February 20, 2003; Accepted May 27, 2003)

\begin{abstract}
Methoxymethylbenzoguanamine resins were analyzed by matrix-assisted laser desorption/ionization timeof-flight mass spectrometry (MALDI-TOF-MS) and electrospray ionization mass spectrometry (ESI-MS). In the case of MALDI-TOF-MS measurements, they could not be characterized because fragmentation occurred considerably. On the ESI-MS measurement, optimization of needle voltage, cone voltage, and cationizing agent made their molecular-related ions intense with little fragmentation. Cluster ions were formed owing to hydrogen bond among their complex components. Gel permeation chromatography (GPC) was used to fractionate the resins. As a result, different oligomer components could be characterized in detail.
\end{abstract}

\section{Introduction}

Amino resins such as melamine resin and benzoguanamine resin are widely used in coating industry as binders or crosslinkers of alkyd resin, polyester, acrylic resin and epoxy resin. They are synthesized as follows. At first, melamine or benzoguanamine is treated with formaldehyde to form hydroxymethyl groups, and then they are converted to alkoxymethyl groups by condensation with alcohol. ${ }^{1), 2)}$ Amino resins are complex mixtures of components with different degrees of hydroxymethylation and alkoxymethylation. They also contain oligomer components. Representative components of methoxymethylbenzoguanamine resin were shown in Fig. 1.

The structure of amino resins has been analyzed by IR and NMR.3) 4) Molar ratios of formaldehyde and alkyl group to melamine or benzoguanamine were determined by NMR analysis. ${ }^{4}$ However, these traditional approaches give their general profile. For further understanding of their physical properties, it is important to obtain more detailed structural information of these complex components. Some groups tried to analyze them by liquid chromatography (LC). ${ }^{5), 6)}$ However, it was difficult to characterize these complex components by UV-Vis and RI detectors, which give little structural information.

Many researchers have been interested in the structural characterization of amino resins by mass spectrometric analysis. Melamine resins were analyzed by FD (field desorption), ${ }^{7), 8)}$ FAB (fast atom bombardment), ${ }^{8), 9)}$ and TSP (thermospray). ${ }^{10), 11)}$ Fragmentation

*a) Analysis Center, Dainippon Ink and Chemical, Incorporated (1-3 Takasago, Takaishi, Osaka 592-0001, Japan)

*b) Department of Applied Chemistry, Kansai University (3-335 Yamatecho, Suita, Osaka 564-8680, Japan) occurred during the measurements, because amino resins are thermally labile. Therefore, it was difficult to characterize them by the mass spectrometric measurements using these ionization methods. Matrix-assisted laser desorption/ionization (MALDI) ${ }^{12)-14)}$ and electrospray ionization (ESI) ${ }^{15)-17)}$ have been developed as effective soft ionization methods. Many researches on the application of these technique have been reported to analyze high molecular weight and thermally labile compounds, which otherwise were difficult to be analyzed by other ionization methods. ${ }^{18-20)}$ Nielen et al. reported ESI-MS analysis using gel permeation chromatography (GPC), capillary electrophoresis (CE), and LC. ${ }^{21)}$ However, the characterization of the oligomer components was insufficient, because the fragmentation occurred under their condition.

In this report, we examine ESI-MS and MALDI-TOFMS analysis of benzoguanamine resin. Our purpose is to search for the optimum condition to detect their molecular-related ions.

\section{Experimental}

Methoxymethylbenzoguanamine resins were obtained by the reaction of benzoguanamine, paraformaldehyde, and methanol as described in literature. ${ }^{1)}$ After the reaction, methanol and formaldehyde were removed at $90^{\circ} \mathrm{C}$ under vacuum and then dissolved into 3-methoxy-3-methylbuthanol (MMB). Two types of resins A and B were synthesized; A (weightaverage molecular weight $\left(M_{w}\right)=225$, number average molecular weight $\left.\left(M_{n}\right)=220, M_{w} / M_{n}(D)=1.16\right)$ contains a little amount of oligomer component, and resin $\mathrm{B}$ $\left(M_{w}=454, M_{n}=340, D=1.34\right)$ does many oligomer components. TOSOH GPC 8010 was used for the GPC fractionation using four TSKgel G2000H8 (TOSOH) as GPC column. Two mL of $7 \mathrm{wt} \%$ sample solution was injected. Chloroform was used as eluent at a flow rate 


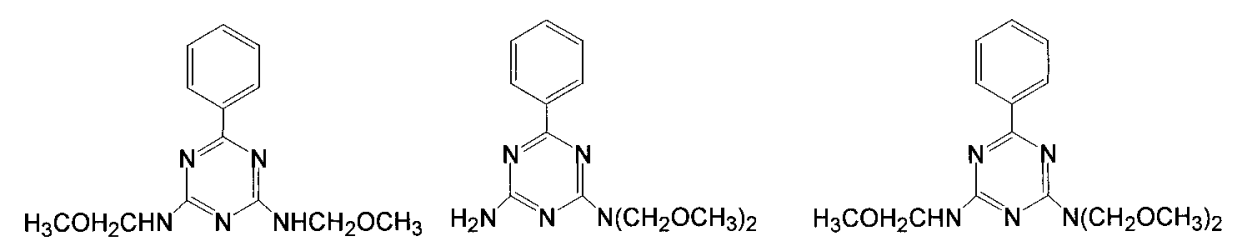

(a) $M W=275$ $(1,2,2)$<smiles>COCCN(CCOC)c1nc(-c2ccccc2)nc(N(CCOC)COC)n1</smiles>

(c) $M W=363$ $(1,4,4)$ (b) $M W=319$

$(1,3,3)$<smiles>CCN(COC)c1nc(-c2ccccc2)nc(N(C)COC)n1</smiles>

(d) $M W=562$

$(2,5,4)$

Fig. 1. Typical structures included in methoxymethyl-benzoguanamine resin. Components of the resin were abbreviated as $(a, b, c)$ : a, number of benzoguanamine; b, adduct number of formaldehyde; c, adduct number of methanol.

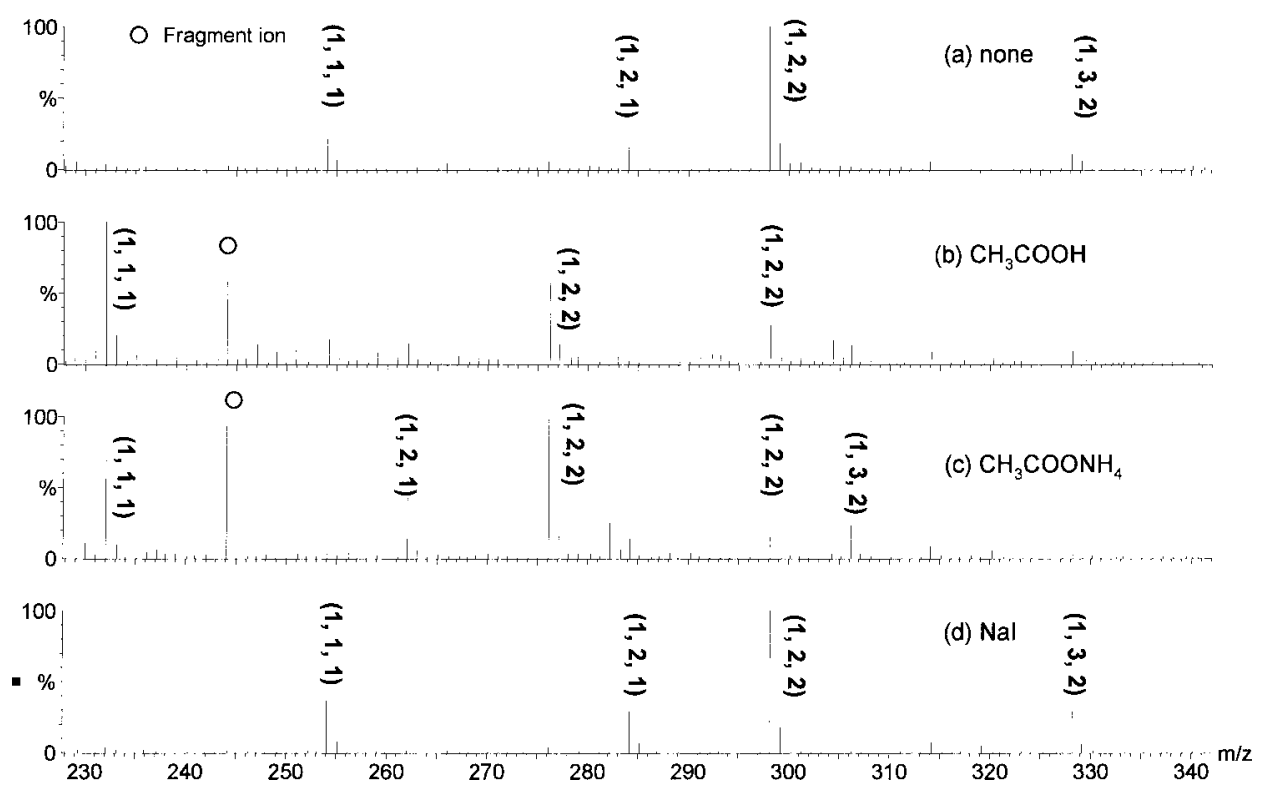

Fig. 2. Effects of cationizing agents on ESI mass spectra for benzoguanamine resin: (a) none, (b) $\mathrm{CH}_{3} \mathrm{COOH}(0.1 \mathrm{v} / \mathrm{v} \%),(\mathrm{c})$ $\mathrm{CH}_{3} \mathrm{COONH}_{4}(0.01 \mathrm{M})$, (d) $\mathrm{NaI}(0.05 \mathrm{mM})$ with sample concentration $50 \mu \mathrm{g} / \mathrm{mL}$, needle voltage $\mathrm{HV}=3.0 \mathrm{kV}$, and cone voltage $\mathrm{CV}=30 \mathrm{~V}$.

$5 \mathrm{~mL} / \mathrm{min}$.

Average molecular weight of benzoguanamine resins and their GPC fractions were analyzed with $\mathrm{TOSOH}$ GPC 8220 by the use of GPC column TSKgel G5000H $\mathrm{G} 4000 \mathrm{H}_{\mathrm{XL}}, \mathrm{G} 3000 \mathrm{H}_{\mathrm{XL}}$, and $\mathrm{G} 2000 \mathrm{H}_{\mathrm{XL}}$ (TOSOH). A hundred $\mu \mathrm{L}$ of $0.4 \mathrm{wt} \%$ sample solutions were injected. Tetrahydrofuran was used as eluent at a flow rate 1 $\mathrm{mL} / \mathrm{min}$.

Benzoguanamine resin (1 mg) and $\mathrm{NaClO}_{4}(1-10 \mathrm{mg})$ were dissolved in acetonitrile $(1 \mathrm{~mL})$, and the solution was mixed with equal volume of saturated matrix solutions in acetonitrile. The mixture was applied on the stainless target and dried at room temperature. $\alpha$-Cyano-4-hydroxybenzoic acid (CHCA), 2,5-dihydroxybenzoic acid (DHB), and dithranol were used as matrix molecules. Positive ion MALDI spectra were obtained in reflectron mode using AXIMER CFR (Shimadzu) fitted with a pulsed nitrogen laser (337 nm). Monoisotopic peaks of CHCA $(m / z 190.1)$, angiotensin II $(m / z$ 1047.2), and insulin (human) $(m / z 5808.7)$ were used for the mass calibration.

ESI mass spectra were obtained with a single quadrupole mass spectrometer ZQ-4000 (Waters, USA) in the positive ion mode. A methanol sample solution $(10-100 \mu \mathrm{g} / \mathrm{mL})$ containing the cationizing agents $\mathrm{NaI}$, $\mathrm{CH}_{3} \mathrm{COONH}_{4}$, or $\mathrm{CH}_{3} \mathrm{COOH}$ was infused by syringe pump at a flow rate $10 \mu \mathrm{L} / \mathrm{min}$. The needle voltage (HV) was set at $1.5-5.0 \mathrm{kV}$, and the cone voltages $(\mathrm{CV})$ were varied, 15 to $50 \mathrm{~V}$. The ion source temperature was $80^{\circ} \mathrm{C}$ and cone gas flow was $50 \mathrm{~L} / \mathrm{min}$. The desolvation $\mathrm{N}_{2}$ gas flow was set at $350 \mathrm{~L} / \mathrm{h}$ and temperature at $150^{\circ} \mathrm{C}$. 

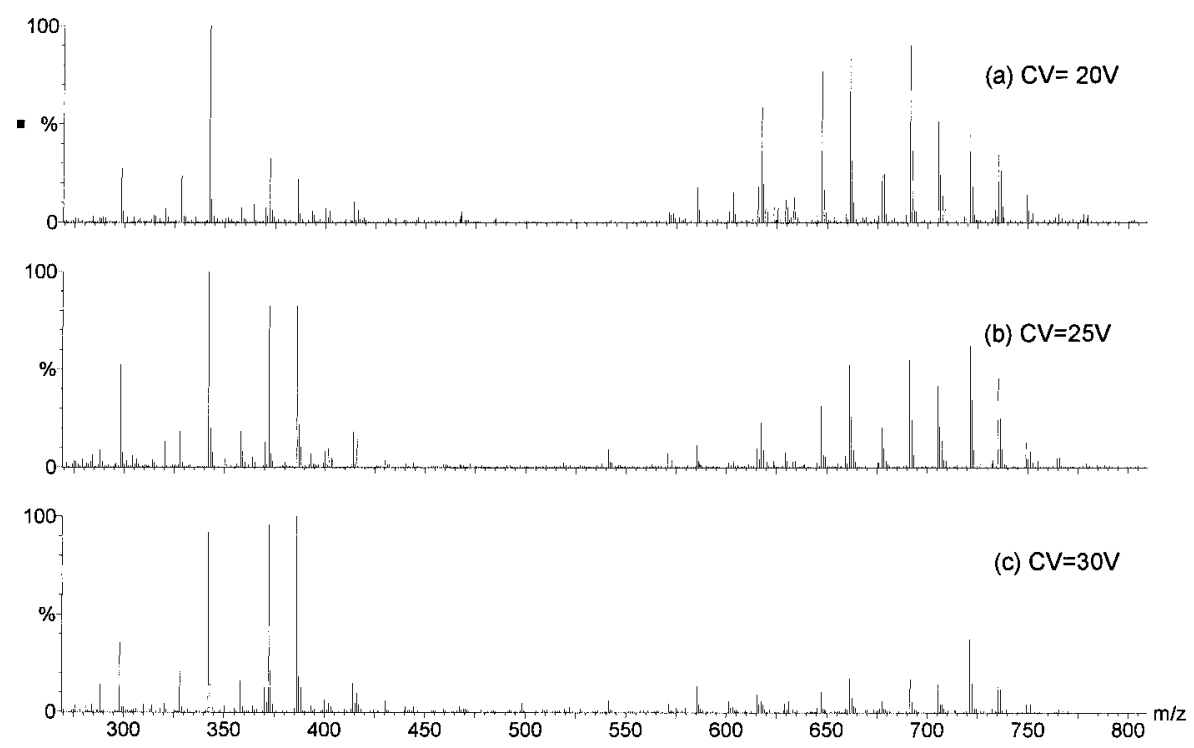

Fig. 3. Effect of cone voltage on ESI mass spectra: (a) $\mathrm{CV}=20$, (b) 25, (c) $30 \mathrm{~V}$ with sample concentration $100 \mu \mathrm{g} / \mathrm{mL}$ and $\mathrm{HV}=3.0 \mathrm{kV}$.
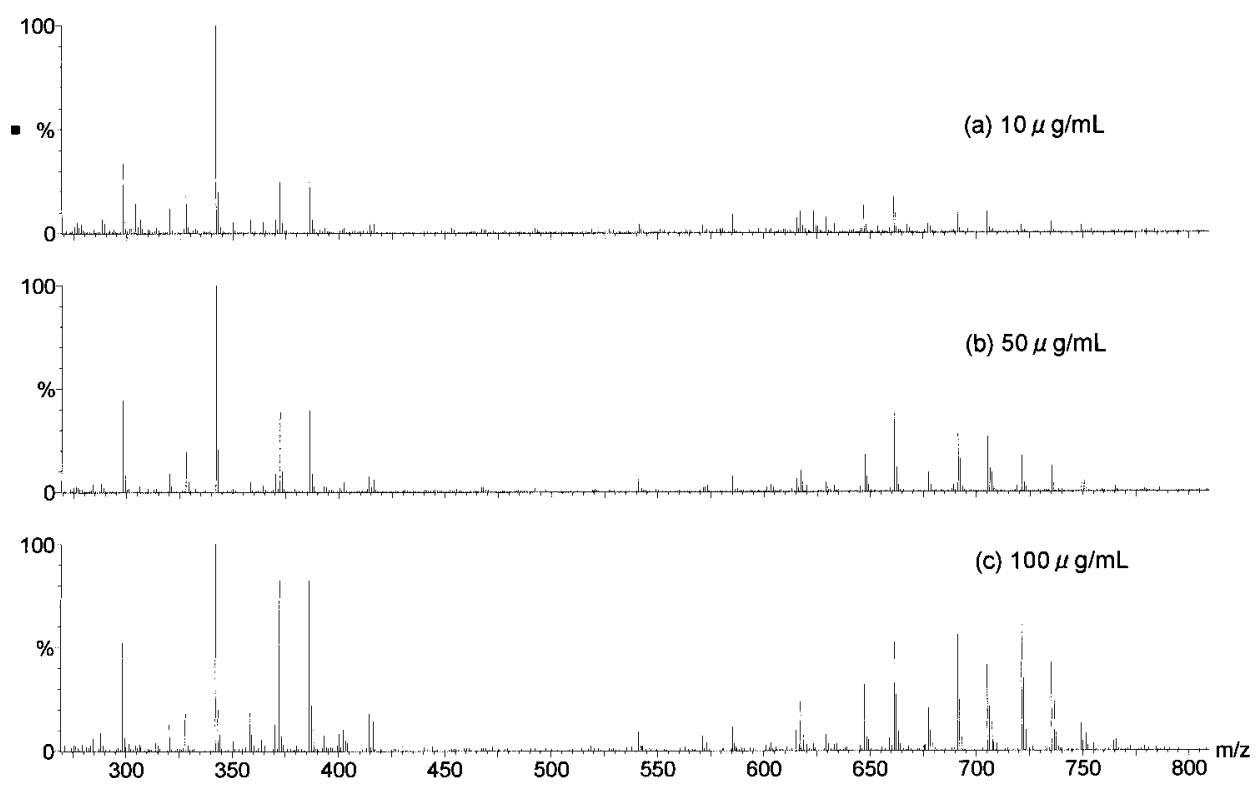

Fig. 4. Effect of sample concentration on ESI mass spectra: (a) 10, (b) 50, (c) $100 \mu \mathrm{g} / \mathrm{mL}$ with $\mathrm{HV}=3.0 \mathrm{kV}$ and CV $=25 \mathrm{~V}$.

\section{Results and Discussion}

Benzoguanamine resins were analyzed by MALDITOF-MS. The effects of matrix molecule, laser power, and amount of cationizing agent $\mathrm{NaClO}_{4}$ were investigated. Among DHB, CHCA, and dithranol, CHCA matrix gave the most intense peak. $\mathrm{Na}^{+}$adduct and protonated molecular-related ions were detected. In spite of the optimization of matrix molecule, laser power and amount of $\mathrm{NaClO}_{4}$, the fragmentation occurred. The fragment ions were generated by the elimination of some methanol molecules from the molecular related ions. ${ }^{7-10), 21)}$ It indicates that MALDITOF-MS is not suitable for the detection of benzoguanamine resins.

Benzoguanamine resins were also analyzed by ESI-MS. In order to intensify the molecular-related ions with little fragmentation, the optimum conditions for the ESI-MS measurement were investigated using resin $\mathrm{A}$.
The effect of cationizing agents was examined by the use of $\mathrm{CH}_{3} \mathrm{COOH}, \mathrm{CH}_{3} \mathrm{COONH}_{4}$, and NaI. Mass spectrum in the range of $m / z 230-340$ at $\mathrm{HV}=3.0 \mathrm{kV}$ and $\mathrm{CV}=30 \mathrm{~V}$ was shown in Fig. 2. Without cationizing agent, $\mathrm{Na}^{+}$adduct ions were detected with weak fragment ions [Fig. 2(a)]. When the sample solutions contain $0.1 \mathrm{v} / \mathrm{v} \% \mathrm{CH}_{3} \mathrm{COOH}^{18)}$ or $0.01 \mathrm{M} \mathrm{CH}_{3} \mathrm{COONH}_{4}{ }^{10), 11)}$ as reported in the ESI-MS analysis of melamine resins, $\mathrm{Na}^{+}$adduct and protonated ions were observed [Figs. 2(b), (c)]. However, intense protonated fragment ion was detected at $m / z 244$, which is generated by the elimination of a methanol molecule from the component $(\mathbf{1}, \mathbf{2}, \mathbf{2}) .^{7-10), 21)}$ The use of NaI made the molecularrelated ions intense with little fragmentation [Fig. 2(d)]. Generally, fragmentation for $\mathrm{Na}^{+}$adduct ions is less than for protonated ions. ${ }^{22), 23)}$ Sodium salts as cationizing agents are suitable for ESI-MS measurements of thermally labile compounds such as amino resins. The effect of $\mathrm{NaI}$ concentration, varying $0-0.1 \mathrm{mM}$, with a constant resin concentration $(50 \mu \mathrm{g} / \mathrm{mL})$ was studied. 

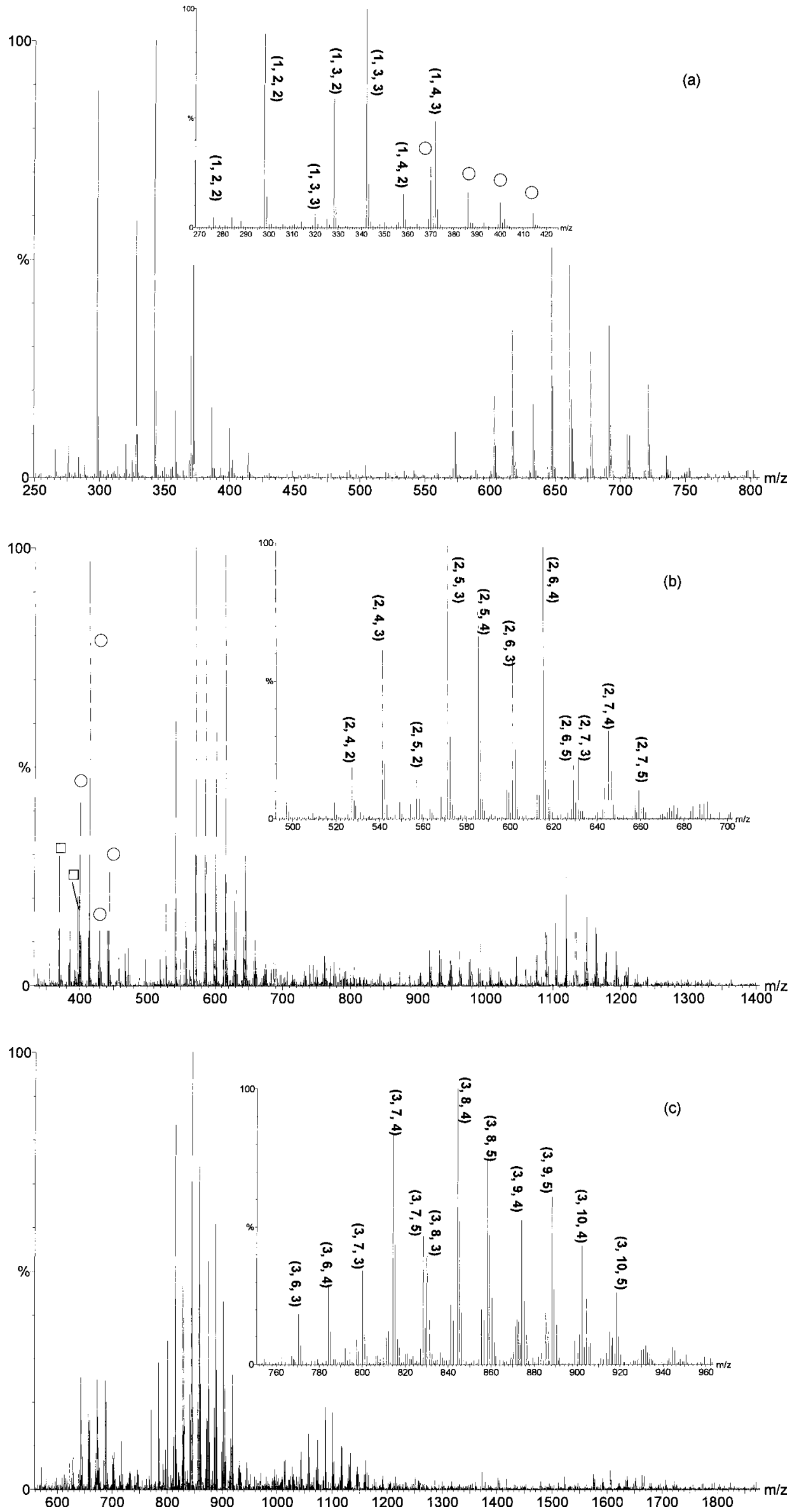

Fig. 5. ESI mass spectra of the GPC fractions of benzoguanamine resin: (a) $\mathbf{f}-\mathbf{1}$, (b) $\mathbf{f}-\mathbf{2}$, and (c) $\mathbf{f}-\mathbf{3}$ with sample concentration $100 \mu \mathrm{g} / \mathrm{mL}, \mathrm{HV}=3.0 \mathrm{kV}$ and $\mathrm{CV}=25 \mathrm{~V}$. $\bigcirc$; components which contain MMB; $\square$, polyoxymethylene. 
With increase of $\mathrm{NaI}$ concentration to $0.05 \mathrm{mM}$, the ion intensities increased. At the concentration more than $0.05 \mathrm{mM}$, the dependence of $\mathrm{NaI}$ concentration was little.

The effect of $H V$, varying $1.5-5.0 \mathrm{kV}$, was studied at $\mathrm{CV}=30 \mathrm{~V}$. In the range of $\mathrm{HV}<1.5 \mathrm{kV}$, no ions was detected. At $\mathrm{HV}>2.0 \mathrm{kV}$, the ion intensities increased with HV. However, at $\mathrm{HV}>3.5 \mathrm{kV}$, a fragment ion $(\mathrm{m} / \mathrm{z} 244)$ increased. The effect of $\mathrm{CV}$, varying $15-50$ $\mathrm{V}$, was also studied at $\mathrm{HV}=3.0 \mathrm{kV}$. The ion intensities were the largest at $\mathrm{CV}=40 \mathrm{~V}$. However, at $\mathrm{CV}>30 \mathrm{~V}$, the fragment ion $(m / z 244)$ increased with $\mathrm{CV}$.

The effect of $\mathrm{CV}$ between $20-30 \mathrm{~V}$ was investigated using resin $\mathrm{B}$ (Fig. 3). With decrease of $\mathrm{CV}$, dimer ions at $m / z$ 600-760 increased. The effect of the resin concentration was also studied using resin $\mathrm{B}$. In the range of $10-100 \mu \mathrm{g} / \mathrm{mL}$, the dependence of the resin concentration on the total ion intensity was little. However, dimer ions increased with the resin concentration (Fig. 4).

Possibly these ions are present as true dimer ions or as cluster ions with hydrogen bond among the monomer components. For example, the peak at $m / z=691$ is the $\mathrm{Na}^{+}$adduct ion of true dimer component $(2,9,3)$ or the $\mathrm{Na}^{+}$adduct cluster ion between $(\mathbf{1}, 3,3)$ and $(\mathbf{1}, \mathbf{4}, \mathbf{3})$, or $(1,3,2)$ and $(1,4,4)$ etc.

Resin B was divided into three fractions using GPC to characterize oligomer components; $\left(M_{w}, M_{n}, D\right)=$ $(263,254,1.04)$ for $\mathbf{f}-\mathbf{1},(549,512,1.07)$ for $\mathbf{f}-2,(956,863$, 1.11) for $\mathbf{f}-3$. The mass spectra of these fractions were shown with the assignments of their main components in Fig. 5. The GPC measurement indicates that $\mathbf{f}-\mathbf{1}$ has few true dimer components, whereas the ESI-MS spectra show intense peaks due to the dimer ions [Fig. 5(a)]. This indicates that cluster ions are formed through hydrogen bond among the monomer units. The MS spectrum shows f-2 contains monomer, dimer and trimer components. In the case of $\mathbf{f}-3$, single $\mathrm{Na}^{+}$ adduct dimer, trimer and tetramer ions were detected with tetramer ions of double $\mathrm{Na}^{+}$adduct at $\mathrm{m} / z$ 600750. The peaks at $m / z 370,400,414,430$, and 444 are due to $\mathrm{Na}^{+}$adduct ions of benzoguanamine components which contain MMB molecules [Figs. 5(a), (b)]. This indicates that MMB can react the hydroxymethyl groups instead of methanol. In the MS spectrum of $\mathbf{f}-2$, $\mathrm{Na}^{+}$adduct ions of polyoxymethylene $\left[\mathrm{CH}_{3} \mathrm{O}\left(\mathrm{CH}_{2} \mathrm{O}\right)_{n}\right.$ $\left.\mathrm{CH}_{3}\right]$ at $m / z 369(n=10)$ and $399(n=11)$ appeared.

\section{Conclusion}

ESI-MS was suitable for the analysis of benzoguanamine resins, but not MALDI-MS. Optimization of the ESI conditions enabled to detect the molecularrelated ions without fragmentation. In the ESI-MS spectra, the oligomer ions could not been different- iated from the cluster ions which are formed through hydrogen bond. Therefore, GPC fractionation for pretreatment of ESI-MS analysis was useful for detailed characterization of the oligomer components.

\section{Acknowledgment}

This work was supported partly by CREST of JST (Japan Science and Technology) and by a Grant-in-Aid for Scientific Research from the Ministry of Education, Science, Sports and Culture of Japan.

\section{References}

1) H. Ohno, Kobunshi Kagaku, 20, 443 (1963).

2) W. J. Blank, J. Coat. Technol., 51, 61 (1979).

3) T. Ishikawa, K. Akiyama, and T. Wada, Shikizai Kyokaishi, 34, 1 (1961).

4) H. Schindlbauer and T. Anderer, Die Angew. Makromol. Chem., 79, 157 (1979).

5) S. Kawai, H. Nagano, and T. Maji, J. Chromatogr., 479, 467 (1979).

6) H. Oguri, Shikizai Kyokaishi, 55, 812 (1982).

7) J. Saito, S. Toda, and S. Tanaka, Netsu Kokasei Jushi, 1, 18 (1980).

8) A. Shiokawa, unpublishued results.

9) E. Longordo, L. Papazian, and T. Chang, J. Liq. Chromatogr., 14, 2043 (1991).

10) T. T. Chang, Anal. Chem., 66, 3267 (1994).

11) T. T. Chang, Progress in Org. Coatings, 29, 45 (1996).

12) M. Karas, D. Bachmann, and F. Hillenkamp, Int. J. Mass. Spectrom., 78, 53 (1987).

13) M. Karas and F. Hillenkamp, Anal. Chem., 60, 2299 (1988).

14) K. Tanaka, H. Waki, Y. Ido, S. Akita, Y. Yoshida, and T. Yoshida, Rapid Commun. Mass Spectrom., 2, 185 (1988).

15) C. M. Whitehouse, R. N. Dreyer, M. Yamasita, and J. B. Fenn, Anal. Chem., 57, 675 (1985).

16) J. B. Fenn, M. Mann, C. K. Meng, S. F. Wong, and C. M. Whitehouse, Science, 246, 64 (1989).

17) R. B. Cole, "Electrospray Ionaization Mass Spectrometry," Wiley, New York (1997).

18) G. Montaud and R. P. Lattimer (eds.), "Mass Spectrometry of Polymers," CRC, Boca Raton (2001).

19) S. D. Hanton, Chem. Rev., 101, 527 (2001).

20) G. F. Swiegers and T. T. Malefetse, Chem. Rev., 100, 3483 (2000).

21) M. W. F. Nielen and H. J.F. M. Van de Ven, Rapid Commun. Mass Spectrom., 10, 74 (1996).

22) R. Chen, A. M. Tseng, M. Uhing, and L. Li, J. Am. Mass Spectrom., 12, 55 (2001).

23) S.Okuno, M. Ohmoto and R. Arakawa, Eur. J. Mass Spectrom., 9, 97 (2003).

Keywords: Matrix-assisted laser desorption/ionization timeof-flight mass spectrometry (MALDI-TOF-MS), Electrospray ionization mass spectrometry (ESI-MS), Benzoguanamine resin, Cluster ion, Gel permeation chromatography (GPC), Fractionation 